\title{
COVID-19, perspectiva e implicaciones para la práctica del dermatólogo
}

El ejercicio médico del año 2020 será recordado por la pandemia causada por el SARS-CoV-2 y la enfermedad debida a este agente infeccioso, la COVID-19, zoonosis descrita por primera vez a finales de 2019 en Wuhan, China. Rápidamente esta se extendió a todos los rincones del planeta gracias a factores como la presencia de individuos oligosintomáticos $y$ asintomáticos transmisores de la infección, que se trasladaban libremente entre ciudades y países, y al alto grado de contagiosidad de este nuevo virus.

El ambiente de temor y tragedia inundó nuestros espacios cotidianos, cambiando nuestra forma de vivir y asumir el día a día. Para los médicos, llevar sobre los hombros el peso de enfrentar, en muchas ocasiones con escasos recursos y elementos de protección personal, una explosión de casos en los servicios hospitalarios y de urgencias, la necesidad de los distintos entes gubernamentales de movilizar recursos, elaborar la normatividad del estado de emergencia, toque de queda y cuarentena; y por parte de los científicos, enfilar todos los esfuerzos hacia el estudio de los mecanismos de patogénesis y al desarrollo de medicamentos y vacunas. Escuelas y universidades vacías, el reto de mantener las aulas abiertas desde la distancia, capacitar maestros, tratar de cerrar la brecha social y procurar el acceso tecnológico a los estudiantes.

Convencer a la población de la necesidad del uso de tapabocas, el lavado de manos y mantener las distancias físicas ha sido tarea titánica. Incluso ahora, varios meses después, nos encontramos con individuos que, a falta de conciencia, ponen en riesgo su salud y la de los demás. Nunca hemos estado tan atentos al impacto del comportamiento propio sobre el destino de los demás. Infortunadamente, a medida que el tiempo pasa, tenemos noticias de nuestros familiares y amigos enfermos y el luto y la despedida son realidades inminentes y cercanas.

Para los dermatólogos, además de ajustar nuestra práctica implementando teleasistencia, también tuvimos que aprender a reconocer las distintas manifestaciones clínicas de la COVID-19, su polimorfismo lesional, que incluye el brote tipo sabañones, el maculopapular, el urticarial, el livedo reticular y la necrosis. Interesante cómo las manifestaciones clínicas guardan relación con el pronóstico ${ }^{(1)}$. Este amplio espectro clínico confronta nuestro quehacer y nos lleva a ampliar el abanico de diagnósticos diferenciales.
Los sabañones son más frecuentes en los niños, los adultos jóvenes y, en general, los pacientes con formas leves de COVID-19, y en cerca del $60 \%$ de los casos se presentan luego de la negativización de las pruebas de PCR. El dermatólogo, cuando observe estas lesiones, además de los tradicionales diagnósticos de vasculitis, vasculopatía, enfermedad autoinmunitaria y oclusión vascular, debe considerar la posibilidad de COVID-19, incluso en ausencia de este antecedente, dado que los sabañones pueden presentarse luego de la infección asintomática.

El brote maculopapular, el livedo reticular y la necrosis se presentan en adultos y coinciden con los síntomas característicos de la COVID-19, como tos, fiebre, odinofagia, anosmia y disgeusia, asociándose a peor pronóstico y mayor mortalidad ( $2 \%$ para formas maculopapulares y $10 \%$ para el livedo y la necrosis). Es de resaltar que el livedo puede observarse transitoriamente en sujetos jóvenes sin implicaciones de gravedad. Las formas vesiculares entran en el diagnóstico diferencial de otras infecciones como varicela y herpes simple diseminado.

Entre los mecanismos de patogénesis se describen la acción directa 
del virus sobre las células infectadas, la hiperactivación del sistema inmunitario y los efectos debidos a los tratamientos administrados, a manera de toxicodermias; sin embargo, es mucho lo que a este respecto está por comprenderse. De forma interesante, el bien conocido receptor del SARS-CoV-2, el de la enzima convertidora de angiotensina 2 (ECA2), está presente en la capa basal de la epidermis, las células endoteliales de la vasculatura dérmica y en el tejido anexial ecrino.

Los eventos inmunitarios relacionados con las formas graves incluyen la inducción de una tormenta de citocinas proinflamatorias, como la interleucina 1 (IL-1), la IL-6 y el factor de necrosis tumoral alfa (FNT-a), el estado de hipercoagulabilidad, la coagulación intravascular diseminada y el síndrome de activación macrofágica. También se describe una deficiente producción de anticuerpos, linfopenia de células T y NK, e inmunodeficiencias relacionadas con defectos en la producción de interferones tipo I (2).

Otro aspecto que ha requerido especial cuidado es el enfoque de las patologías dermatológicas en manejo con terapia inmunosupresora e inmunomoduladora; es así como expertos de distintos países han elaborado consensos y recomendaciones a este respecto. Se planteaban serias dudas sobre el inicio de la terapia biológica, terapia sistémica convencional, esteroides en dosis altas, y han sido muchos los pacientes analizados en junta médica para la toma de decisiones. Ahora el panorama es un poco más claro $\mathrm{y}$, en general, seguimos formulando a los pacientes los medicamentos que requieran y recomendando unas medidas preventivas estrictas y una vigilancia estrecha ante los síntomas que sugieran COVID-19. Es importante reconocer que los individuos con patologías reumatológicas que reciben esteroides sistémicos en dosis iguales o mayores a $10 \mathrm{mg} / \mathrm{d}$, una terapia bastante empleada en dermatología, tienen dos veces más riesgo de hospitalización por desarrollar COVID-19 grave que aquellos que no estaban en tratamiento con esteroides ${ }^{(3)}$. Lo anterior plantea la necesidad de un acompañamiento cercano e información completa a los pacientes y sus familias.

Cerramos el 2020 con adelantos en la generación de vacunas: la de Pfizer y BioNTech con tecnología ARN y una eficiencia reportada del $95 \%$, que requiere congelación de $-70^{\circ} \mathrm{C}$, lo que supone dificultades en su conservación y distribución. La de Moderna, también con tecnología ARN y eficiencia del $94,5 \%$, puede conservarse a $-20^{\circ} \mathrm{C}$ (temperatura del congelador convencional actual). La de AstraZeneca y Oxford, con una eficiencia del $70 \%$, puede conservarse refrigerada entre 2 y $8^{\circ} \mathrm{C}$. Y la Sputnik V, con una eficiencia del $91,4 \%$, apta para mantenerse en condiciones de refrigeración. De todas estas vacunas se requieren dos dosis.

Algunos países iniciaron en diciembre la vacunación masiva y estamos a la espera de los resultados en vida real. Es aquí y ahora donde la equidad social y el desarrollo científico deben demostrar ser patrimonio de la humanidad. Para países como Colombia es importante proveer los recursos y las disposiciones para la adquisición y distribución de las vacunas para toda la población.
Culminamos el 2020 con muchos aprendizajes, con avances en el acercamiento virtual y en la adquisición de otras competencias educativas y herramientas, valorando mucho más los regalos más grandes y también los más sencillos, el contacto humano, el compartir, la familia, los amigos, el trabajo. Que no olvidemos lo difícil que ha sido estar aislados, lo complejo que ha sido llorar la despedida de los seres queridos desde la distancia y todo el personal de salud fallecido en esta pandemia. Que luego de esto seamos mejores y recordemos que para la enfermedad y el dolor todos somos iguales. Que nuestro quehacer médico siga estando a la altura que la nueva realidad nos exige. 


\section{REFERENCIAS}

1. Galván-Casas C, Català A, Carretero-Hernández G, Rodríguez-Jiménez P, FernándezNieto D, Rodríguez-Villa Lario A, et al. Classification of the cutaneous manifestations of COVID-19: a rapid prospective nationwide consensus study in Spain with 375 cases. Br J Dermatol. 2020;183(1):71-77. doi: 10.1111/bjd.19163

2. García LF. Immune Response, Inflammation, and the Clinical Spectrum of COVID-19. Front Immunol. 2020;11:1441. doi: 10.3389/fimmu.2020.01441

3. Gianfrancesco M, Hyrich KM, Al-Aldely S, Carmona L, Danila MA, Gossec L, et al. Characteristics associated with hospitalisation for COVID-19 Global Rheumatology Alliance physican-reported registry. Ann Rheum Dis. 2020;79(7):85966. doi: 10.1136/annrheumdis-2020-217871
Margarita María Velásquez

PROFESORA, UNIVERSIDAD

de Antioquia, Centro de INVESTIGACIONES DERMATOLógICAS CIDERM, SECCIÓN De Dermatología

EdITORA, REVISTA DE LA AsoCIACIÓN COLOMBIANA DE Dermatología Y Cirugía DERMATOLógica

ORCID HTTPS://ORCID.ORG/ 0000-0001-8604-6488

COMO CITAR: VELÁSQUEZ MM, COVID-19, PERSPECTIVA E IMPLICACIONES PARA LA PRÁCTICA DEL DERMATÓlOGO. REV ASOC COLOMB DERMATOL. VOL 28(4): OCTUBRE - DICIEMBRE, 2020, 300-302.

DOI: HTTPS://DOI.ORG/10.29 176/2590843X.1545oRG/10 $.29176 / 2590843 X .1545$ 